\title{
Teaching Learners to Exchange Information over Telephone
}

\author{
Valentina Tsybaneva1, Oxana Maletina ${ }^{2}$, and Elena Malushko, ${ }^{3, *}$ \\ ${ }^{1}$ Volgograd State Academy of Postgraduate Study, Foreign Language Chair, Volgograd, Russia, valentinatsybaneva@yandex.ru \\ ${ }^{2}$ Volgograd State University, Foreign Language Communication Department, Volgograd, Russia, o.maletina@ volsu.ru \\ ${ }^{3}$ Volgograd State University, English Philology Department, Volgograd, Russia, e.malushko@volsu.ru
}

\begin{abstract}
This article is devoted to the problem of raising learners' awareness of exchanging information over the telephone. The paper highlights the results of analysing the specific features of the organisation of the telephone conversation for exchanging information. It presents a brief summary of skills and knowledge needed for telephone conversation and discourse analysis of this kind of conversation. Moreover, cognitive (familiarity with the topic, genre and interlocutors and processing demands), affective (feeling towards the topic and / or participants and selfconsciousness) and performance (absence of eye-contact, gestures, possibility to monitor interlocutor's responses, degree of collaboration, discourse control, environmental conditions and time pressure) factors are discussed in the article. The activities aimed at raising learners' awareness of a telephone conversation process to exchange information are given with rationale and methodological support.
\end{abstract}

\section{Introduction}

Speaking on the phone is one of the most essential skills for everyday and business communication for many learners due to the rapid increase in mobile phone ownership and Internet telephony. It is also one of the most difficult aspects for them. It makes sense to provide students with telephone skills practice and raise their confidence of how to make calls in English.

Without "paralinguistic clues" [1], [2] which characterise face-to-face communication, understanding and responding naturally to the person learners speaking to over the telephone is the most challenging kind of oral communication. Consequently, it is important to develop students' speaking skills such as speaking with appropriate intonation, using necessary discourse markers and proper grammar and vocabulary.

From our own teaching experience, we can conclude that students who attend General and Business classes mostly need telephoning skills for exchanging information. This research is beneficial for the learners and the teachers as it is aimed at describing some strategies, skills and discourse features needed for communication over the telephone.

\section{Helping learners to exchange information over the telephone: strategies and teachers' technics}

The genre of exchanging information over the telephone has a transactional function as it is "primarily messageoriented" [3], [4]. The main purpose of this genre is to exchange information taking into consideration that speakers cannot rely on their paralinguistic knowledge. When speaking on the phone, listeners "have to rely on other means, such as intonation, tempo, and pausing, to gauge the current state of their interlocutor's turn" [1], [2], [5].

\subsection{Analysis of features}

\subsubsection{Organisation of the telephone conversation for exchanging information}

The organisation of the telephone conversation for exchanging information can be viewed as the following:

Table 1. The organisation of the telephone conversation for exchanging information.

\begin{tabular}{|l|l|}
\hline A (caller) & B (receiver) \\
\hline Opening & $\begin{array}{l}\text { Greeting, (naming the } \\
\text { organisation) }\end{array}$ \\
\hline $\begin{array}{l}\text { Greeting, giving } \\
\text { reasons for calling }\end{array}$ & $\begin{array}{l}\text { Directing to the person } \\
\text { according to the request or } \\
\text { giving the information, asking } \\
\text { for clarification (follow words } \\
\text { in italics for 2 next stages) }\end{array}$ \\
\hline $\begin{array}{l}\text { Asking for } \\
\text { clarification, giving } \\
\text { the clarification }\end{array}$ & Giving the required information \\
\hline
\end{tabular}

* Corresponding author: e.malushko@volsu.ru 


\begin{tabular}{|l|l|}
\hline & $\begin{array}{l}\text { if possible) / giving the } \\
\text { required information } \\
\text { possible) }\end{array}$ \\
\hline 2 previous stages can be repeated several times \\
\hline Closing and \\
\hline $\begin{array}{l}\text { Summing up and } \\
\text { thanking }\end{array}$ \\
\hline & Thanking for calling \\
\hline
\end{tabular}

\subsubsection{Skills and knowledge needed for exchanging information over the telephone}

Skills:

- recognizing the appropriate moment to get a turn;

- holding the floor while you have your turn;

- recognizing when other speakers are signalling their wish to speak;

- signalling the fact that you are listening [1].

Knowledge:

-sociocultural - both participants of the telephone conversation know about social values and norms and the way they are realized through the language (opening / closing structures, functional language, etc.);

- extralinguistic - both speakers know the topic, have background knowledge relevant for the topic, realise the context and make reference while speaking, and to some extent have shared knowledge (elliptic, redundant words, phrases etc);

- grammar can be characterized by the use of less complex grammar structures (Present Tenses, Direct Speech, Tags Questions for clarifying information, etc.);

-vocabulary (except the one related to the topic) includes words and expressions used by speakers to show their attitude to what is being said - probably, maybe, really, actually;

-pronunciation is crucial. One particular aspect which is significant for telephone conversation is intonation. It aids speakers to understand where they can take turns as pronunciation separates the streams of speech into blocks (tone units) and the significant ones are stressed (prominent) [6].

\subsubsection{Discourse analysis of telephone conversation for exchanging information}

The telephone conversation for exchanging information is interactive (unless you leave a message on the answering machine) and planned (presuming caller knows why he / she is phoning). It follows Grice's four maxims: Quantity (be as informative as required); Quality (true contribution); Relation (relevant contribution) and Manner (be brief and orderly) [7], [8]. These points are significant and contribute a lot to the strategies needed for the telephone conversation.

Discourse strategies [1]

1) Opening and closing

-- Hello, I'd like to speak to Mr....

-- Hello, this is Miss ...... calling from .... Is Ms ...... available, please? My name's ....

- Thank you for contacting me.

-Thank for getting in touch.
2) Feedback in conversation / back-channelling

-borrowing by the speaker a segment of other speakers' utterance;

-is repetition of one's own utterance;

-uh-huh, really? (I'm listening)

3) For managing turn-taking one speaker on the phone is listening while the other is speaking. "Discourse markers" [9] are used to signal one's intentions to hold the conversational turn and mark boundaries in the talk. Speakers can use the following phrases:

-that reminds me (I'm continuing the same topic);

-by the way (I'm indicating a topic change);

-yes, but I know (I'm indicating agreement with a negative idea).

4) Filling pauses using pauses fillers - uh, um, er, erm - or vagueness expression - sort of / I mean / repeats [10].

5) Using functions as the relation between language and its contexts of use:

-Hold on a moment, please.

-I'll put you through to Miss...

-I'll ask her to call you back as soon as she is free.

-Could you ask her to call me back, please? My number is ......

-Could you give him a message, please?

Requiring

-I want to speak with someone about V+ing / noun/.

-Who could I speak to about V+ing / noun/?

\section{Clarifying a request}

-I meant ...

-No, that would be...

-Yes, that's right.

- That's exactly what I mean.

6) Positive or negative appraisal [11]:

-spatial deixis - here / there / this / that

-temporal deixis - now / this / then / that

-personal deixis $-I /$ me / you / your.

7) Being familiar with adjacency pairs [7]:

Question:

-Could you ask ..... to ....for me?

Preferred responses:

-My pleasure.

-I'll do that now.

Dispreferred response:

-I won't be able to..... because ....

\subsection{Learning Problems and Teaching Issues}

While speaking over the telephone for exchanging information, speakers should bear in mind the following factors:

-cognitive (familiarity with the topic, genre and interlocutors and processing demands);

-affective (feeling towards the topic and / or participants and self-consciousness);

-performance (absence of eye-contact, gestures, possibility to monitor interlocutor's responses, degree of collaboration, discourse control, environmental conditions and time pressure) [9]. 
Frequently, these factors are the sources of learners' problems while speaking on the phone.

\subsubsection{Problems caused by cognitive factor}

Firstly, students may not be aware of the topic of conversation. Precisely, they do not have any background or sociocultural knowledge about what is to be discussed. For example, if they never enrol for any language school over the telephone in their own country, it definitely causes problems when they will be phoning a language school in Great Britain. They may use direct questions, what is impolite in English in this case, and have difficulty in asking tags questions for clarification of information. They may say, "You ask me about the date, really?" It is common with Russian students. As it is the telephone conversation, students have to rely more on pronunciation, in particular, intonation of the other speaker. Moreover, they have to speak clearly and slower than usually minding the intonation. It is complicated for them, as they want to be fluent.

Secondly, they are not familiar with some specific features of this genre. Learners hesitate about the style formal, informal or neutral - and if they need to use special jargon or other in-group language forms. The lack of genre knowledge also means that they can have problems with discourse strategies. Students hardly know some closing phrases even though they know opening ones. They end the telephone conversation without thanking the receiver using simple "Bye" or nothing. Use of adjacency pairs can also be inappropriate:

\section{Question:}

- Could you speak slowly, please?

Responses:

-Do you think I speak quickly?

Some students believe that silence means that "they agree with what the speaker is saying". It is due to the fact that they are not aware about back-channelling and how they are used or they do not use them in their native or first language (L1). Additionally, learners are afraid of pauses as they do not know how to fill the pauses; they start feeling frustrated (though it is one of the conversation characteristics). They are not aware when to take the floor.

Thirdly, learners tend not to follow the stated structure of the telephone conversation. As Howarth notices many learners seem "to feel that use off planning time before speaking is "unnatural", something that native speakers never do" [12], [13]. They feel frustrated when teacher asks them to think over what they are going to say as they are not completely sure that it can help them to be fluent. It also results in the failure of the whole telephone conversation as they claim they "don't know what to say further". Unlike adult learners, most teenagers prefer text messages to calls. Moreover, it can be a negative issue for teaching them how to talk over the telephone.

\subsubsection{Problems caused by affective factor}

In real life, it can be actually stressful for students to communicate over the phone. Generally, students do not know strategies needed for telephone conversation. To raise their awareness teacher should provide students with more practice. It can help to develop and raise their confidence.

\subsubsection{Problems with performance}

The main difficulty of a telephone conversation for exchanging information for learners is the absence of non-verbal communication, precisely, eye-contact and gestures of the other speaker. Moreover, telephone conversations are normally shorter than face-to-face. So learners are under the time pressure. The lack of functions used for telephone conversation can lead to misunderstanding and even failure of the conversation. For example:

-Hi! I need to know....

-Hello! Give the phone to ....

The misuse of telephone functions can be caused by the interference of L1, especially if students try to translate each word.

\subsection{Raising learners' awareness of telephone conversation for exchanging information}

Checking background knowledge is possible with the help of a quiz or questions:

- Do you ever make telephone calls in English? Why? What for?

- When is it better to make a phone call than to send an email?

- What problems have you had when talking in English on the phone?

- In general. Why is talking on the phone is more difficult than talking face-to-face?

- How can you prepare for telephone calls, and what can you do to make sure there have been no misunderstandings? (Adopted from [14]).

Students can work in pairs and discuss the questions:

Discuss the following questions in pairs:

- What is difficult about making a first-time call to a stranger?

- What can you do to make such calls easier?

- What can you do to establish a relationship with a stranger more quickly?

- How can you make sure that the other person knows who you are and what you want?

- If you have proposed an appointment or a meeting, how can you be sure that the other person has fully understood your intention? (Adopted from [15]).

In case of difficulty, it is useful to think over the same questions using background knowledge in L1. These two activities help the teacher to evaluate the level of knowledge about telephone calls and find out if students are familiar with strategies. The teacher chooses the task according to the students' needs and level. A quiz is more appropriate for Business classes. The teacher can also ask students to brainstorm the topic of conversation in pairs. 
A model of telephone conversation can be given to students to work out its organisation and scheme. Firstly, learners can listen to the conversation for the gist and answer 2 or 3 questions to check the main idea. Secondly, they can have the script of the model(s) to analyse it and in pairs or groups draw the scheme. Providing students cannot find it out, teacher uses Concept check questions (CCQs) such as: Who answers first? What? What is the other speaker saying? etc. If learners are of a lower level, it is reasonable to give them the model and the scheme (for scheme see Analysis of features).

The same model(s) can be used to discuss language and analyse opening and closing, back-channelling and pauses fillers.

Receiver: Green and Handing, good morning!

Jane: Oh, good morning! This is Jane White calling from London. I'd like to speak with Terry Smith.

Receiver: Hold on a moment, please. I'll just find out if she's in the office. Ok. I'll put you through to Miss Smith.

Terry: Good morning! Terry Smith.

Jane: Terry ...er.. it's Jane White from London, Red and Handing. Do you think you could help me with a couple of things?

Terry: Er...sure.

Jane: Um...do you think you could send a copy of the report to London for me?

Terry: Er...yeah, do you want me to ...er fax it, or...or... send by email?

Jane: Oh, er...fax, I think. ...Um...now, let's see, then would you mind arranging accommodation for $\mathrm{Mr}$ Berlund, he needs it for Friday night.

Terry: Friday night, sure. Hotel Continental, as usual?

Jane: Mm, that's right. Oh, could you write down our new fax number?

Terry: Sure.

Jane: 7896584008612

Terry: Sorry, could you repeat that?

Jane: Yeah..7-8-9-6-5-8-4-0-0-8-6-1-2

Terry: Great! Do you think you could send me your report today?

Jane: Um...Terry, I'm sorry, but I ...I can't. I've got these letters to finish by 6 and it's just....

Terry: Oh...mm ...just ok. Thanks for calling me. Bye.

Jane: Thank you. Bye.

Using the context of the telephone conversation students can guess the meaning and purpose of the underlined words. Afterwards, it needs practicing pronunciation. Usually, learners find this activity very encouraging as they think about their telephone conversations in L1.

For students of a high level listening to different activities can be used. They help them to identify different versions of opening and closing fillers and how they influence the style of the telephone conversation. Learners listen to the conversations, for example,

- Sorry. Must go. Got another meeting!

- Ok. See you at seven.

- Thanks for calling.
The students write down the opening and closing phrases. Then students discuss in pair or small groups their style. The pronunciation of these conversations can be practised further. Learners should know about a rise in pitch at the end of the tone units, which signals of continuation, and a fall in pitch suggests completion. It helps to develop their ability of taking-turns.

The strategies needed for the telephone conversation of exchanging information should be discussed with learners. Handouts with 12 tips

Twelve telephone tips:

1. Fax ahead if you want to make sure the other person has time to prepare for the call.

2. Make sure you have with you all the documents you will need before you dial the number.

3. The other person may not understand you easily, so try to speak SLOWLY and CLEARLY.

4. The other person can't see your reaction, so always CONFIRM that you have (or have not) understood each point that has been made. Do not pretend you have understood when you have not.

5. The other person can not see what a nice person you are, so make sure sound POLITE and AGREEABLE.

6. The other person has not got all day, so make sure your call is BRIEF.

7. The other person is getting an impression of your firm while talking with you, so make sure that you sound EFFICIENT.

8. Do not rely on your memory: make notes during a call and rewrite these notes immediately afterwards as a record of the call.

9. Smile while you are talking. Your listener can "hear" your smile.

10. Do not try to be funny - you may be misunderstood.

11. Do not interrupt the other person: let them finish what they want to say.

12. Send a follow-up fax or email to confirm any important details (especially prices and numbers) say that you both have a written record of them (Adopted from [15]).

The mentioned above tips are actually the strategies. Five further questions are given to students for discussion.

Discuss the tips given above and answer the following questions:

- Which do you think are the five most important tips?

- Which of the tips do you disagree with? Why?

- Which of the advice do you already follow when making or receiving a phone call in English?

- Which of the points do you feel least confident about if you are using English on the phone?

- What aspects of telephoning in English can be improved by practice? (Adopted from [15])

They work in pairs or in groups and answer the questions. The teacher can monitor and decide about the feedback: students share their ideas or they discuss all strategies and the possibility of their implementation in real life.

Activities for practice 
The grammar needed for the telephone conversation is mostly Present Tenses, Tags Questions and Indirect Questions. To get some revision and grammar practise some activities can be used. It is a paraphrase which can be beneficial for developing students' productive vocabulary.

Telephone functions are presented with the help of listening or reading text. Some of them are specific and appropriate only for the telephone conversations. Teacher can elicit other functions, which are suitable for exchanging information using CCQs.

Table 1. Telephone Functions for Exchanging Information (based on the following books [4], [14], [15], [16], [17]).

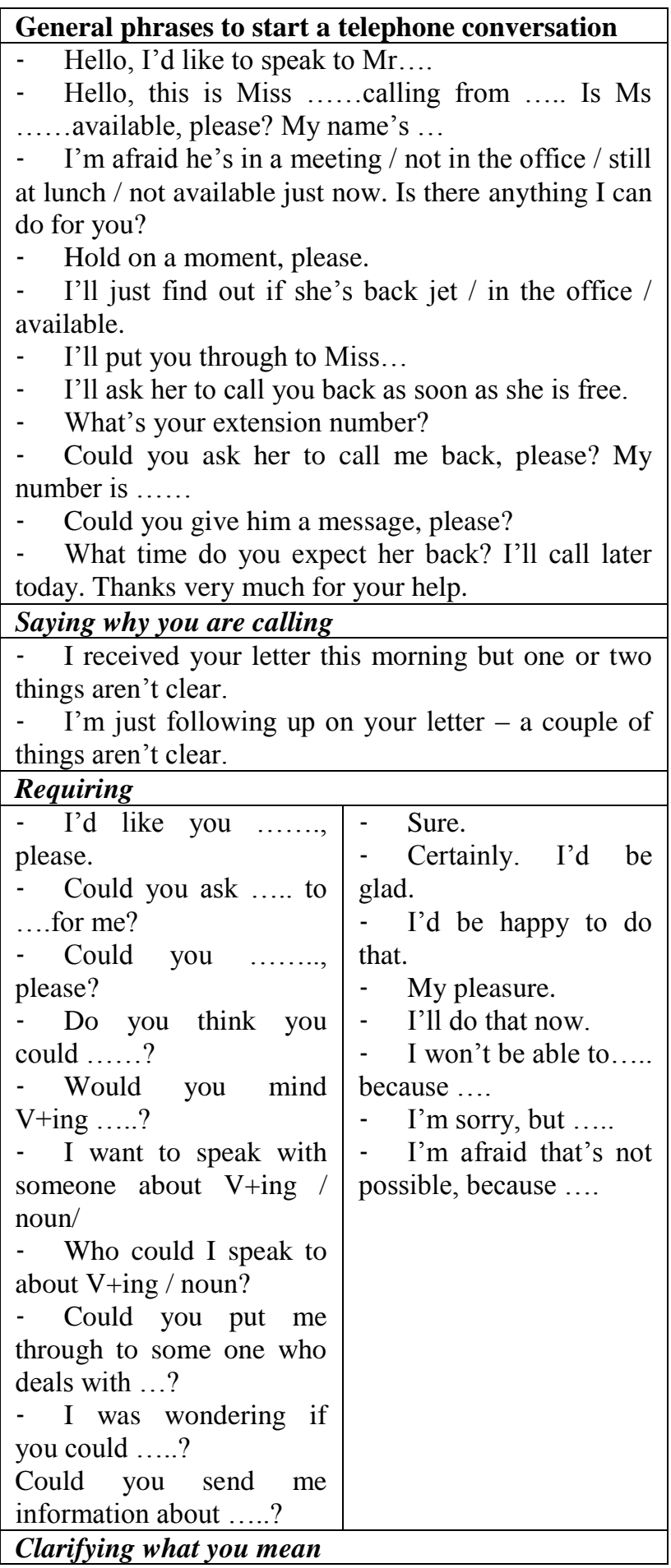

- $\quad$ I meant ...

- No, that would be....

- Yes, that's right.

That's exactly what I mean.

Checking personal details

- Let me see if I've written that correctly.

Let me just check those details. So that...

\section{Saying you don't understand}

- I'm afraid you're speaking a bit too fast for me.

- Inter.... What? I'm sorry, I don't know this word. What does it mean?

- I'm afraid I don't understand what you mean.

- I'm afraid I don't follow you exactly.

What exactly do you mean by that?

\section{Describing line problems}

- We were cut off.

- This is a terrible line.

- There is a lot of interference on this line.

- I'm afraid I can't hear you very well.

- I'm afraid we have a crossed line.

- It's very noisy here - I can hardly hear you.

\section{Offering to help}

- Can I give you a - Yes, please. Thanks hand?

- Would like a hand - No, thanks. I think I with....?

- Shall I.....?

Would you like me to .....?

- If you need any help,

just let me know.

\section{Asking clarification}

- May I check a couple of points with you?

- Could you clarify a couple of things for me?

- Could I ask you a couple of questions about your letter?

- Did you m... Could you possible speak a little slower?

- Excuse me? I didn't catch that.

- Sorry, could you repeat that?

- Could you explain that to me again, please?

- Sorry, how do you spell that?

- Can you speak up a bit?

- $\quad$ Did you mean .....?

\section{Asking permission}

- May I ....?

- $\quad$ Do you mind if I ....? - B $\quad$ By all means.

- Could I .....?

- Is it right if I ....? - No, I'm not afraid ...??

Do you think I could - I'm sorry but ....

Suggesting a solution

- I think I have to call you back.

- Can you call back?

- I'm going to hang up and call you back?

Could you try calling back?

Thanking and concluding

- Thank you very much. That's all I need to know.

- That's all I wanted to check. I'll get that off to ...you. 


\begin{tabular}{|ll|}
\hline Thanking \\
\hline$-\quad$ Thank you for calling. \\
- $\quad$ Thank you for contacting me. \\
- $\quad$ Thank for getting in touch. \\
\hline
\end{tabular}

Functions can be written on the board and their pronunciation should be practised. Paraphrase activities can be helpful with memorising form and meaning of the functions.

As pronunciation is critical for telephone conversation, it requires more practice. Some sentences with functions can be presented and with students of high level, they can be transcribed. These sentences are to be drilled with the teacher.

The second focus is to highlight the importance of the telephone functions for clarification or repetition of information:

Asking clarification or repetition

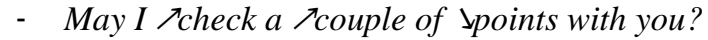

- Could you Tclarify a Tcouple of ذthings for me?

- Could I Jask you a Icouple of Jquestions about your \letter?

- Could you possibly $\nearrow$ speak a little \slower?

- Excuse Tme? I didn't ذcatch that.

- TSorry, could you re ১peat that?

- Could you Jexplain that to me a \gain, please?

- TSorry, how do you ذspell that?

- ILet me Isee if I've ذwritten that cor ১rectly. ILet me just $\nearrow$ check those de ذtails. So that.

There are some activities which can give students the chance to focus on responding to each other naturally, without an eye contact [. Asking a whole group sitting alongside each other without an eye contact and pairs sitting one behind the other can be close to real life communication over the telephone. The first is a roleplay.

A You are calling to Mr Anderson to ask him to send you a book today. Give your address. Ask to remind Mrs Smith about the presentation of the book: Book by $\mathrm{Mr}$. Anderson, London, Friday 16.00, Central Hall. Be polite.

B You are Mr Anderson. You need to know the address. You can't hear the address. Ask the caller to repeat the address. Ask for clarification. Ask the caller to repeat the same information again. Be polite.

The second involves very close and alternative listening as student B works out who A is. Students practise telephone conversation using functions and appropriate intonation. Teacher monitors and asks some students to present to the whole class. Alternatively, students work in groups of 3 or 4 . While 2 of them are performing, the other(s) is / are observing and answering the questions.

Observer's guidelines:

- Does each speaker sound agreeable, polite and efficient?

- Do they sound natural and sincere?

- Does each speaker's tone create the right impression?

- Are they speaking clearly?

- Is the information they have given correct?
- Have they both covered all the essential points?

- Is it the kind of call you would like to receive yourself? (Adopted from [15, 32]).

Finally, they discuss the conversations in groups.

\section{Conclusion}

Evidently, this topic is essential and needs further working on. In the subsequent research, more specific features of the telephone conversation can be discussed. It is crucial to develop students' awareness of different telephone functions, which can also be useful for the face-to-face communication and provide them with sufficient practice. Thus, it is critical to focus on the teachers' professional competence in planning and selecting the content for foreign language practice classes.

\section{References}

1. S. Thornbury, D. Slade, Conversation: From Description to Pedagogy (CUP, 2006)

2. S. Thornbury, How to Teach Speaking (Longman, 2007)

3. G. Brown, G. Yule, Teaching the Spoken Language (CUP, 1983)

4. B. Jean Naterop, R. Revell, Telephoning in English (CUP, 1997)

5. E. Malushko, O. Maletina, V. Tsybaneva, Advances in Social Science Education and Humanities Research (ASSEHR) 97, 175-180 (2017)

6. A. Dolzhikova, V. Kurilenko, Yu. Biryukova, N. Rumyantseva, E. Kulikova, E. Tumakova, Journal of International Migration \& Integration. Springer, 1-14 (2018)

7. G. Cook, Discourse (OUP 1989)

8. A. Dolzhikova, V. Kurilenko, Yu. Biryukova, N. Pomortseva, O. Shcherbakova, SGEM International Multidisciplinary Scientific Conference on Social Sciences and Arts, 371-379 (2016).

9. S. Thornbury, How to Teach Speaking (Longman, 2007)

10. S. Thornbury, Beyound the Sentence. Introducing Didcourse Analysis, 64-65 (Macmillan, 2005)

11. D. Nunan, Discourse Analysis, 118 (Penguin English, 1993)

12. P. Howarth, Modern English Teacher 10(1) (2001)

13. P. Howarth, Modern English Teacher 10(2) (2001)

14. G. Brook-Hart, Business Benchmark (CUP, 2006)

15. New International Business English: Student's Book (CUP, 1996)

16. J. Hughe, Telephone English (Macmillan, 2006)

17. K. Bruce, Telephoning (Longman, 1994)

18. E. Malushko, O. Maletina, V. Lizunkov, V. Tsybaneva, International Multidisciplinary 
Scientific Conferences on Social Sciences and Arts, 481-487 (2016)

19. N.L. Shamne, E.V. Shishkina, Vestnik Volgogradskogo Gosudarstvennogo Universitetaseriya 2-yazykoznanie 16 (2), 143-151 (2017) 